\title{
Gradients in Planarian Regeneration and Homeostasis
}

\author{
Teresa Adell, Francesc Cebrià, and Emili Saló \\ Department of Genetics and Institute of Biomedicine, University of Barcelona, Av. Diagonal 645, \\ E-08028 Barcelona, Catalonia, Spain \\ Correspondence: esalo@ub.edu
}

Planarian regeneration was one of the first models in which the gradient concept was developed. Morphological studies based on the analysis of the regeneration rates of planarian fragments from different body regions, the generation of heteromorphoses, and experiments of tissue transplantation led T.H. Morgan (1901) and C.M Child (1911) to postulate different kinds of gradients responsible for the regenerative process in these highly plastic animals. However, after a century of research, the role of morphogens in planarian regeneration has yet to be demonstrated. This may change soon, as the sequencing of the planarian genome and the possibility of performing gene functional analysis by RNA interference (RNAi) have led to the isolation of elements of the bone morphogenetic protein (BMP), Wnt, and fibroblast growth factor (FGF) pathways that control patterning and axial polarity during planarian regeneration and homeostasis. Here, we discuss whether the actions of these molecules could be based on morphogenetic gradients.

\begin{abstract}
Freshwater planarians are bilaterally F symmetrical metazoans of the phylum Platyhelminthes. These animals are unsegmented, acoelomate, and possess well-defined anteroposterior (AP) and dorsoventral (DV) axes. Along the AP axis, we can distinguish an anterior cephalic region containing the brain and, usually, a pair of eyespots, a central region with a pharynx and a ventral mouth opening, and a posterior tail region (Fig. 1A). Planarians are best known for their ability to regenerate complete animals from tiny fragments of their own bodies in 1 wk (for review, see Saló and Baguñá 2002; Reddien and Sánchez-Alvarado 2004; Saló 2006; Sánchez-Alvarado 2006). This ability has attracted the interest of many
\end{abstract}

scientists since long ago (Pallas 1774; Johnson 1822; Morgan 1901). Planarian regeneration requires the production of new tissue from the unique proliferative and pluripotent stem cells known as neoblasts (Handberg-Thorsager et al. 2008). After amputation, neoblasts close to the wound proliferate, giving rise to the regenerative blastema, defined as the unpigmented tissues where the missing tissues will differentiate (Fig. 1B-E). Remarkably, planarian pieces cut at any level along any of its axes can regenerate a whole worm, perfectly proportionate in only a few days (Fig. 1F). The process of tissue regeneration in the wound region from proliferating neoblasts was termed epimorphosis. In addition, a repatterning of the whole

Editors: James Briscoe, Peter Lawrence, and Jean-Paul Vincent

Additional Perspectives on Generation and Interpretation of Morphogen Gradients available at www.cshperspectives.org

Copyright (C) 2010 Cold Spring Harbor Laboratory Press; all rights reserved; doi: 10.1101/cshperspect.a000505

Cite this article as Cold Spring Harb Perspect Biol 2010;2:a000505 
T. Adell, F. Cebrià, and E. Saló
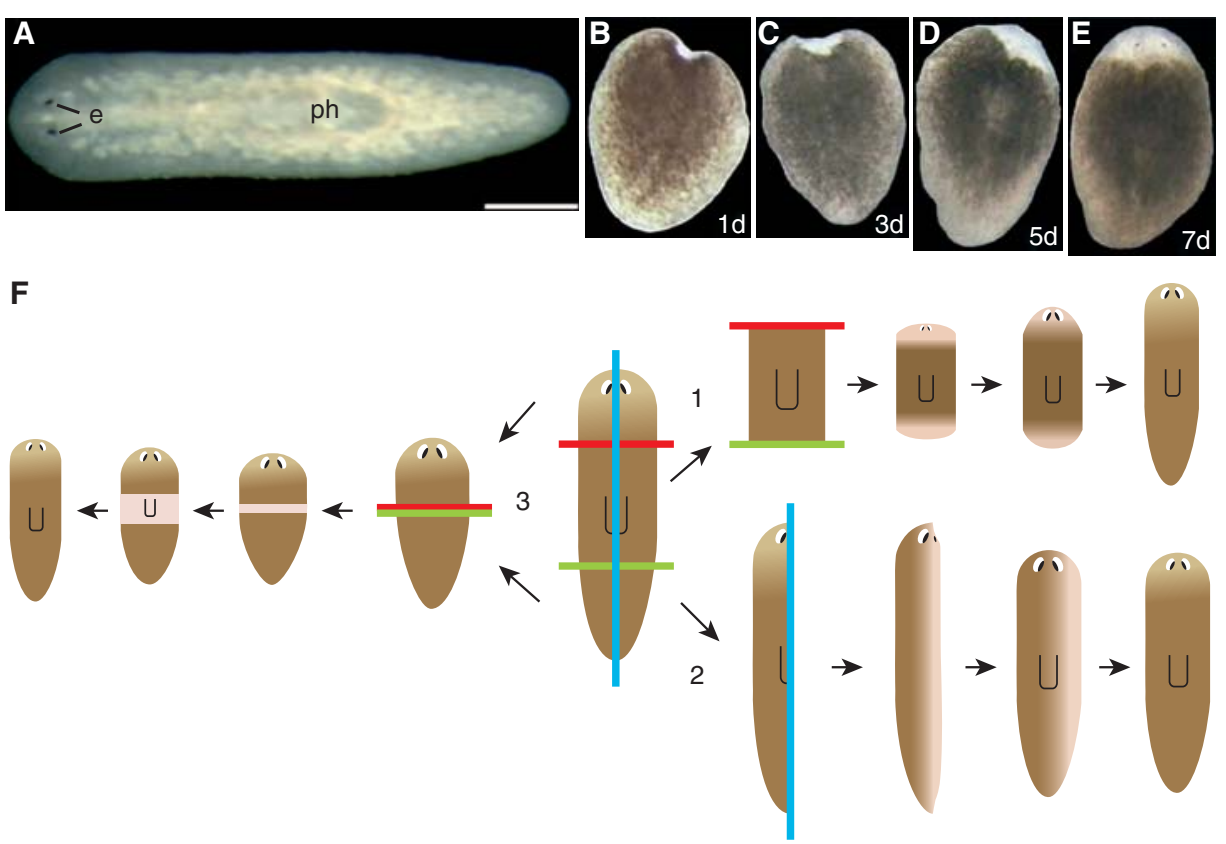

Figure 1. Regenerative capacity of freshwater planarians. (A) Schmidtea mediterranea planarian (top left). (e) Eyespots, (ph) pharynx. Bar, $1 \mathrm{~mm}$. $(B-E)$ Tail pieces at various stages of regeneration (top right). The white tissue in the most anterior tip is the regenerative blastema. Two small eyespots are evident within it after $5 \mathrm{~d}$ of regeneration. $(F)$ Planarians display unique regenerative capacities, as any small fragments from almost anywhere can regenerate a new organism in $2 \mathrm{wk}$. In this diagram, we summarize the main types of planarian regeneration: (1) Terminal regeneration: After transverse sectioning, the anterior end (red line) will regenerate the missing head, whereas the posterior end (green line) will regenerate the missing tail. This indicates that the remaining tissue is polarized and knows what is missing. (2) Lateral regeneration: After longitudinal sectioning (blue line), the old tissue regenerates the missing lateral half. (3) Intercalary regeneration: After joining two distal pieces produced by transverse sections, planarians intercalate the missing region. In that case, cells from each piece participate equally in the production of an intercalary blastema (Saló and Baguñà 1985).

organism is required to recover a complete and proportionate regenerated planarian. This process of remodeling old tissues was termed morphallaxis (Morgan 1901). Together, with the initial studies on planarian regeneration, the first hypotheses suggesting a role of morphogenetic gradients in this process were proposed based on the observation of a differential regenerative capacity along the AP axis (Morgan 1901; Child 1911; Huxley and de Beer 1934).

\section{THE BEGINNING: FROM GRADIENTS OF REGENERATIVE CAPACITY TO MORPHOGENETIC GRADIENTS}

One of the first issues to be analyzed in planarian regeneration was how axial polarity is re-established (Morgan 1904). After the head and tail of a planarian have been cut off, the anterior end of the remaining fragment regenerates a head, whereas the posterior end regenerates a tail (Fig. 1). In general, planarians amputated at any level along the AP axis can regenerate a head; however, the rate of head regeneration decreases posteriorly (Sivickis 1931). Such observations led to the so-called "head-frequency curves" and showed a timegraded regeneration rate along the AP axis. In another set of classical experiments, narrow bipolar regenerating pieces occasionally regenerated two-headed planarians ("Janus heads") (Morgan 1898), indicating that some minimal AP distance in a region of tissue is required to specify polarity. When observing these "Janus 
heads," Child (1911) concluded that polarity consisted of a dynamic gradient along an axis. However, whereas Morgan considered that polarity was determined by structural or substance differences along the axis (Morgan 1905), Child associated polarity with metabolic gradients, suggesting a gradation in the rate of physiological processes along the axis, namely "physiological gradient" (Child 1941; for review, see Brøndsted 1969; Blackstone 2006). Such differential axial activity was revealed by various parameters: (1) The early stimulation of protein synthesis in $\mathrm{C}^{14} \mathrm{O}_{2}$-labeled regenerating planarians was higher for stumps that form heads than in those that form tails (Kohl and Flickinger 1966), and (2) other studies showed an anterior-to-posterior gradient of protein synthesis in intact planarians. In those cases in which protein synthesis was inhibited at an anterior stump, polarity was inverted (Flickinger 1959).

Recently, a gradient of neoblast mitotic activity along the AP axis of intact planarians has been reported (Oviedo and Levin 2007). However, a testable mechanistic framework of metabolic gradients in planarians remains to be developed. Despite the lack of characterization of morphogens in planarians, the axial polarity of these animals has been used to support hypotheses of morphogenetic gradients controlling developing patterns (for review, see Slack 1987). Thus, the positional information theory of Lewis Wolpert (1969), as well as the hypothesis of an organizing center as the source for a morphogen to which competent cells would respond in discrete thresholds (Lewis et al. 1977; Meinhardt 1978), have been theoretical models that have agreed with biological observations. A group of candidate morphogens were described in Hydra (Schaller et al. 1979) and their behavior was explained theoretically by the doublegradient model of Meinhardt and Gierer (1974). During the period between 1976 and 1978 , we tried in vain to isolate such morphogens in planarians (Saló 1984). However, very recently, signaling pathways based on secreted molecules such as bone morphogenetic protein (BMP) and Wnts have been implicated in the establishment and maintenance of planarian axial polarity (Molina et al. 2007; Orii and Watanabe 2007; Reddien et al. 2007; Gurley et al. 2008; Iglesias et al. 2008; Petersen and Reddien 2008; Adell et al. 2009).

\section{THE WNT/ $\beta$-CATENIN PATHWAY \\ REGULATES THE PLANARIAN ANTEROPOSTERIOR AXIS}

The Wnt/ $\beta$-catenin signaling pathway is an evolutionarily conserved mechanism that confers polarity during embryonic development. It specifies the main axis in cnidarians (Wikramanayake et al. 2003) and echinoderms (Logan et al. 1999), and the AP axis in most bilaterians (Holland 2002; Croce and McClay 2006). The Wnt/ $\beta$-catenin signaling pathway also controls cell fate and regulates tissue homeostasis through stem-cell proliferation and differentiation in adult organisms (Reya and Clevers 2005). The binding of Wnts, the secreted elements of the pathway, to the receptors frizzled and coreceptors LRP, leads to the disruption of the $\beta$-catenin "degradation complex," composed by Axin, GSK3, CKI, and APC. Afterwards, $\beta$-catenin, the key intracellular element of the pathway, accumulates in the cytoplasm, enters the nucleus, and activates TCF transcription factors, which regulate the expression of multiple genes. Wingless (Wg), the founding member of the Wnt family, from Drosophila, has been formally demonstrated to act as a morphogen (Strigini and Cohen 2000).

Recent studies have characterized several elements of the Wnt/ $\beta$-catenin signaling pathway in planarians, demonstrating the functional conservation of this pathway in cell-fate determination and axial polarity establishment in these animals (Kobayashi et al. 2007; Gurley et al. 2008; Iglesias et al. 2008; Petersen and Reddien 2008; Adell et al. 2009). Two $\beta$-catenins have been reported from the planarian Schmidtea mediterranea (Iglesias et al. 2008). The silencing of one of

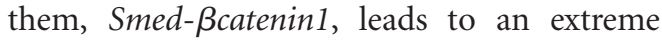
phenotype: "radial-like hypercephalized" planarians, showing large circular cephalic ganglia, together with several ectopic eyes, all 
around the planarian body (Fig. 2G,K). After Smed- $\beta$ catenin 1 silencing, in trunk pieces regenerating both head and tail regions simultaneously, this transformation occurs gradually. Thus, the initial anteriorization of the posterior region and the final "radial-like hypercephalized" phenotype can be followed by the observation of external morphological traits, as well as by molecular markers such as an anti-synapsin antibody, which labels synapses (Fig. 2A,E-G,J,K). First, two new anterior eyes differentiate normally. Then, two ectopic eyes appear posteriorly, followed by the differentiation of ectopic anterior eyes (Fig. 2E,J). Thereafter, additional ectopic eyes differentiate, also posteriorly (Fig. 2F), and finally, "radiallike hypercephalized" planarians are generated (Fig. 2G,K). The severity of the phenotype depends not only on the time of regeneration,

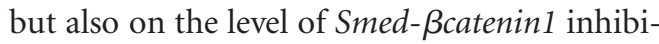
tion, as demonstrated after injection of varying amounts of dsRNA (Fig. 2A,C,D). With the lowest doses ( $1 \mathrm{~d}$ of injection), the phenotype observed is the inhibition of tail regeneration (Tailless phenotype, Fig. 2C). No differentiation of ectopic eyes is seen. After $2 \mathrm{~d}$ of injection, most of the animals adopt a two-headed phenotype (Fig. 2D). These animals also show the differentiation of a second pharynx, oriented in the opposite direction to the wild type (Fig. 2D,I). The most extreme phenotype is not reached with these doses. Only after $3 \mathrm{~d}$ of injection does the "radial-like hypercephalized" phenotype appear (Fig. 2G,K).

It should be noted that the phenotypes obtained with low doses (Tailless and twoheaded planarians with two pharynx) do not evolve to more extreme phenotypes. In contrast, with the highest doses, the different phenotypes, from two-headed to "radial-like hypercephalized," represent a temporal progression, although not all animals reach the most severe anteriorization. In this case, the two-headed planarians do not differentiate a second pharynx; in contrast, the original pharynx appears disorganized (Fig. 2E,J), or even disappears in "radial-like hypercephalized" planarians (Fig. 2G,K). Consistent with these data, the gradual disappearance of posterior and central identities, concomitant to the appearance of the anterior identities, has been demonstrated with cell-specific markers (Iglesias et al. 2008).

Although the penetrance and progression of the transformation is lower, silencing of SmedBcatenin1 in intact planarians also generates the "radial-like hypercephalized" phenotype (Fig. 2L-Q) (Iglesias et al. 2008). The analysis of the progression of the transformation in vivo, and also with molecular markers such as anti-VC1 antibody, which labels the visual axons and the photoreceptors, demonstrates that the dynamics of the transformation is very similar to that observed in regenerating trunk pieces. New ectopic eyes appear first in the tail, followed by the differentiation of ectopic eyes anteriorly (Fig. 2M,P), and then, from both ends, the anteriorization proceeds to transform the whole planarian body (Fig. 2N,Q).

Taken together, these data demonstrate the conservation of the role of the Wnt $/ \beta$-catenin pathway in axial establishment, maintenance, and cell-fate determination in planarians. A classical model of morphogenetic gradient activity originated by a posterior organizer can be proposed to explain the different phenotypes observed after the different doses of SmedBcatenin1 dsRNA injection (Fig. 3). All along the body of wild-type planarians, a gradient of Smed- $\beta$ catenin 1 activity, with its maximum in the posterior region, provides the proper $\mathrm{AP}$ positional information to the cells (Fig. 3A). In wild-type planarians that regenerate posteriorly, after dissection of the tail, high levels of Smed- $\beta$ catenin 1 activity in the posterior blastema lead to wild-type planarians with a normal AP axis differentiation (Fig. 3B). If Smed-ßcatenin 1 activity is inhibited only slightly, just below the level for tail specification, the Tailless phenotype is originated (Fig. 3C). When Smed- $\beta$ catenin 1 activity levels are inhibited just below the level for trunk specification, anterior identities appear in the posterior blastema (Fig. 3D). Classical tissue transplantation experiments show that planarian grafts have inductive capacity and that new ectopic tissue is differentiated by intercalation (Brøndsted 
Gradients in Planarian Regeneration and Homeostasis

\begin{tabular}{|c|c|c|c|c|c|c|c|}
\hline & \multirow{2}{*}{ Phenotype } & \multicolumn{2}{|c|}{$1 \mathrm{~d} \times 3 \mathrm{inj} / \mathrm{d}$} & \multicolumn{2}{|c|}{$2 \mathrm{~d} \times 3 \mathrm{inj} / \mathrm{d}$} & \multicolumn{2}{|c|}{$3 d \times 3 i n j / d$} \\
\hline & & $10 \mathrm{~d}$ & $19 \mathrm{~d}$ & $10 \mathrm{~d}$ & $19 \mathrm{~d}$ & $10 \mathrm{~d}$ & 19d \\
\hline \multirow{6}{*}{ 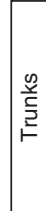 } & Wild type (Image B) & $3 / 5$ & $3 / 5$ & $5 / 9$ & $5 / 9$ & & \\
\hline & Tailles (Image C) & $2 / 5$ & $2 / 5$ & & & $1 / 23(4 \%)$ & $1 / 23(4 \%)$ \\
\hline & Two-headed (Image D) & & & $4 / 9$ & $3 / 9$ & $1 / 23(4 \%)$ & $1 / 23(4 \%)$ \\
\hline & Two-headed with anterior ectopic eyes (Image E) & & & & $1 / 9$ & $21 / 23(92 \%)$ & $4 / 23(17 \%)$ \\
\hline & Two-headed with ant. and post. ectopic eyes (Image F) & & & & & & $10 / 23(44 \%)$ \\
\hline & 'Radial-like hypercephalized' (Image G) & & & & & & $7 / 23(31 \%)$ \\
\hline
\end{tabular}
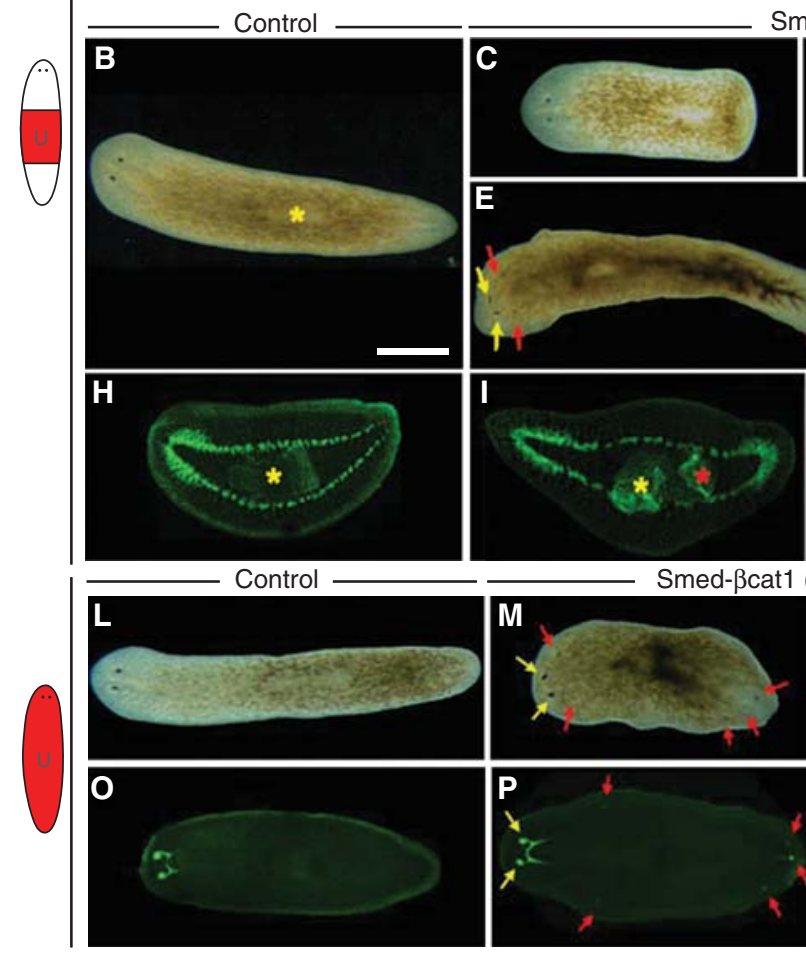

Smed-ßcat1 (-)
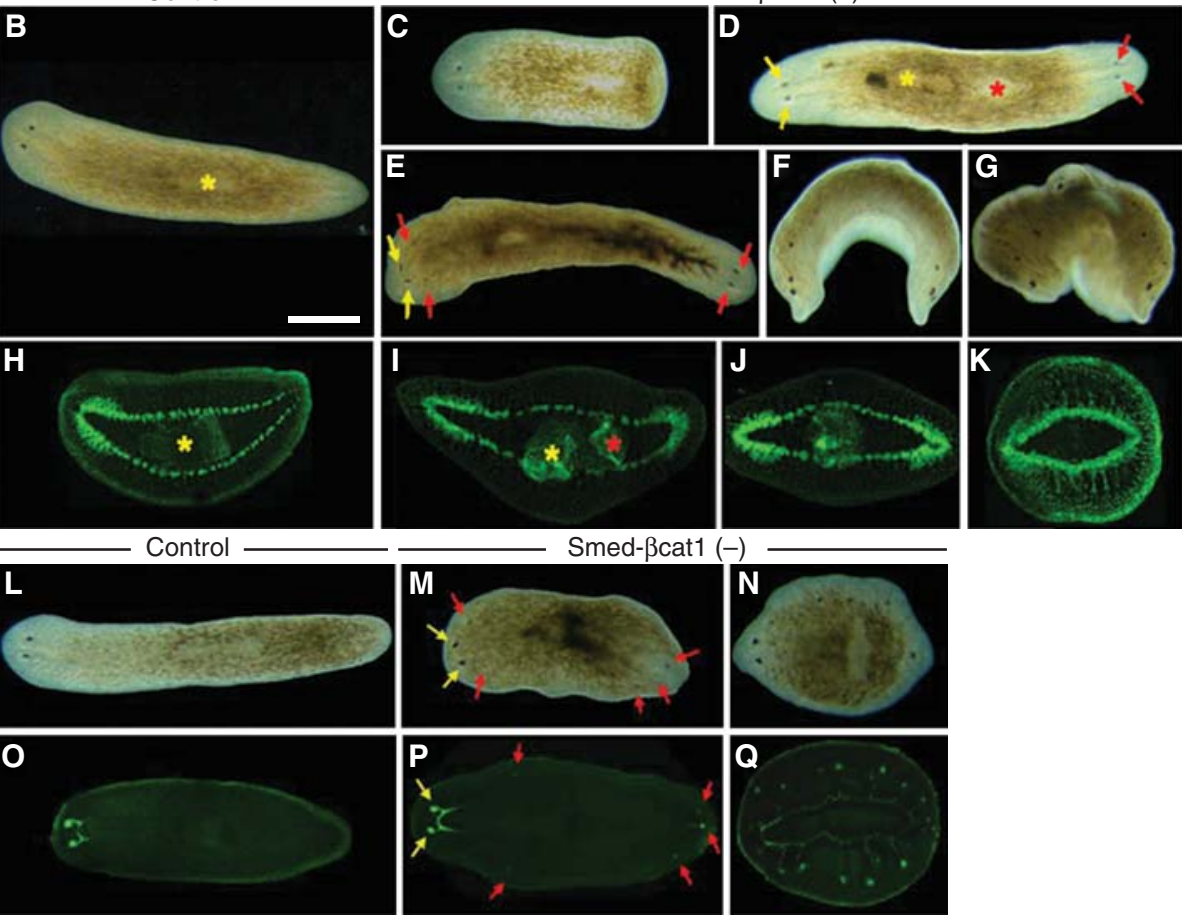

Figure 2. Phenotypes generated after Smed-ßcatenin1 silencing in regenerating and in intact planarians. (A) Quantification of the different phenotypes obtained after Smed- $\beta$ catenin1 silencing in bipolar regenerating trunk fragments, after different doses of dsRNA injection. (d) Days, (inj) injections. $(B-G)$ Stereomicroscope images of live animals originated from bipolar regenerating trunk fragments: Control $(B)$; "tailless" planarians $(C)$; two-headed planarians with a second ectopic pharynx $(D)$; two-headed planarians with anterior ectopic eyes $(E)$; two-headed planarians with anterior and posterior ectopic eyes $(F)$; and "radial-like hypercephalized" planarians $(G)$. (H-K) z-projections of confocal images corresponding to bipolar regenerating trunk fragments immunostained with anti-synapsin antibody: Control $(H)$; two-headed planarians with a second ectopic pharynx $(I)$; two-headed planarians with anterior ectopic eyes $(J)$; and "radial-like hypercephalized" planarians $(K) .(L-N)$ Stereomicroscope images of live intact animals: Control $(L)$; two-headed with ectopic anterior and posterior eyes $(M)$; and "radial-like hypercephalized" planarians $(N)$. (O-Q) z-projections of confocal images corresponding to intact animals immunostained with anti-VC1 antibody: Control $(O)$, two-headed with ectopic anterior and posterior eyes $(P)$; and "radial-like hypercephalized" planarians $(Q)$. Bipolar regenerating animals correspond to $20-25 \mathrm{~d}$ of regeneration. Intact animals in images $M$ and $P$ correspond to $15 \mathrm{~d}$ after the last injection, and images $N$ and $Q$ correspond to $30 \mathrm{~d}$ after the last injection. Yellow asterisks indicate original pharynx, and red asterisks indicate ectopic ones. Yellow arrows indicate normal anterior regenerated eyes, and red arrows indicate ectopic eyes. Bar, $500 \mu \mathrm{m}$. 

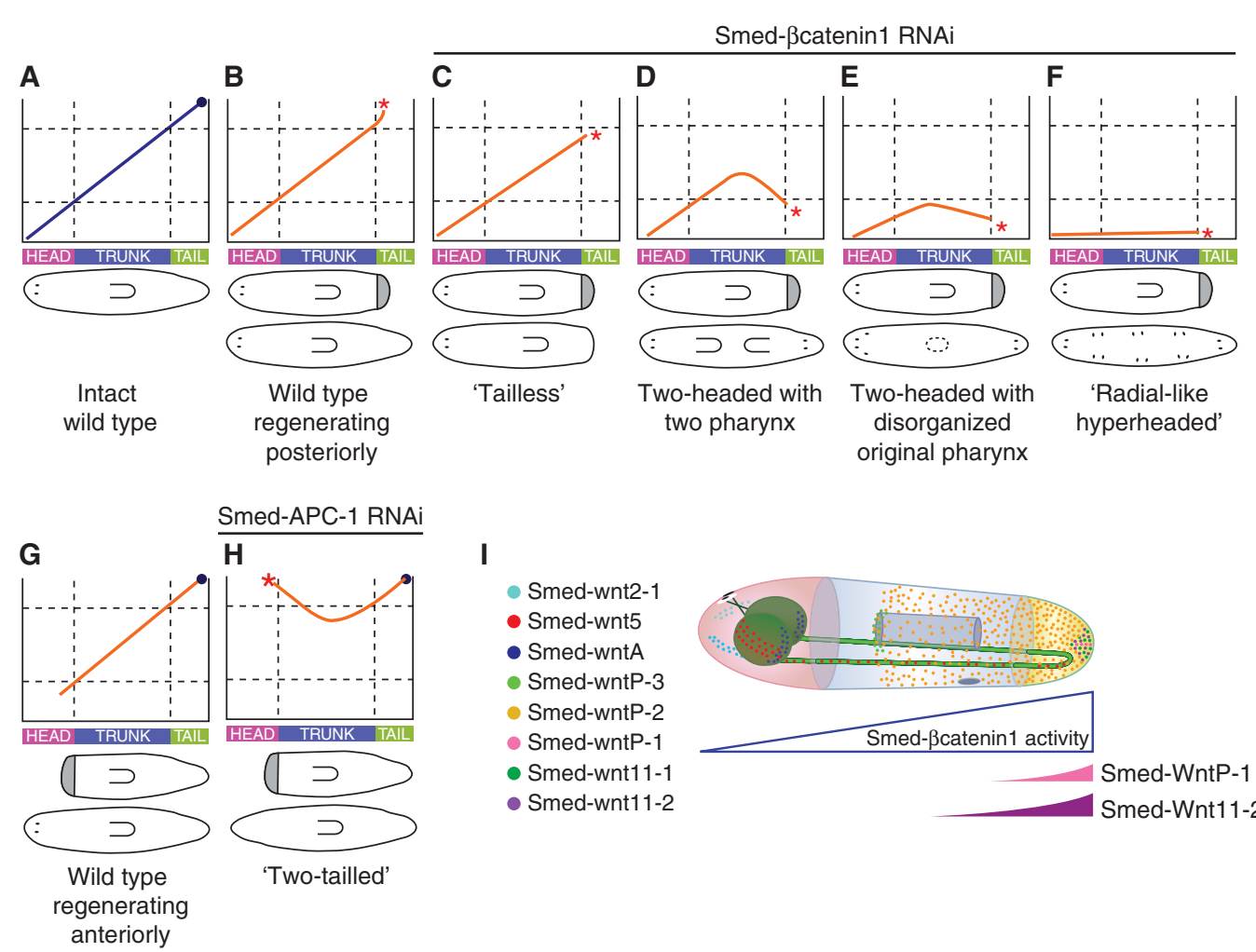

I

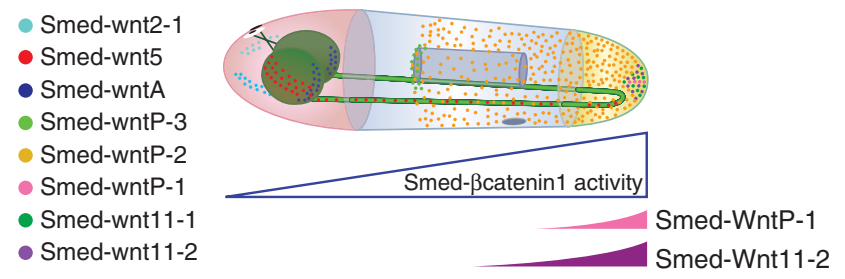

Figure 3. Model of the dynamics and the establishment of a Smed- $\beta$ catenin 1 gradient activity in adult planarians. $(A-H)$ A gradient of Smed- $\beta$ catenin 1 activity, with its maximum in the posterior region, would explain the different phenotypes obtained after the different levels of Smed- $\beta$ catenin 1 inhibition $(C-F)$ and Smed-APC-1 inhibition $(H)$. (blue line in $A$ ) Levels of Smed- $\beta$ catenin 1 activity in intact wild-type planarians; (blue dot in $A, G$, and $H$ ) source of wnt-secreted elements; (red asterisks) levels of Smed- $\beta$ catenin 1 activity in the posterior blastema of regenerating planarians $(C-F)$ and in the anterior blastema after Smed-APC-1 silencing $(H)$; and (orange line) levels of Smed- $\beta$ catenin 1 activity established all along the planarian body during the first regeneration stages. $A$ and $G$ show Smed- $\beta$ catenin 1 activity in wild-type planarians that regenerate posteriorly and anteriorly, respectively. Under each scheme, the corresponding phenotype generated is shown. (I) Graphic representation of eight S. mediterranea wnt expression. All show a restricted expression pattern in specific planarian structures. The putative protein gradient of the 2 posterior wnts that give an anteriorized phenotype after RNAi silencing is shown in the corresponding color. These gradients would have morphogenetic activity, and pattern the AP axis, through regulation of Smed- $\beta$ catenin 1 activity.

1969). Therefore, in this case, the new ectopic posterior head can induce the differentiation of a second pharynx, orientated in the opposite direction to the original, because the levels of Smed- $\beta$ catenin 1 in the trunk region of these planarians are still high enough to allow central identity differentiation. When Smed- $\beta$ catenin 1 activity is even lower, a posterior head also appears in the posterior region, but it does not induce the differentiation of a second pharynx because Smed- $\beta$ catenin 1 activity is below the level for trunk specification all along the planarian body (Fig. 3E). Accordingly, even the original pharynx appears disorganized. When Smed- $\beta$ catenin 1 activity is abolished completely, the whole planarian body adopts an anterior identity, originating the "radial-like hyperheaded" phenotype (Fig. $3 \mathrm{~F})$. In contrast, when APC-1, a component of the $\beta$-catenin degradation complex, is silenced, a tail appears in regenerating planarians, instead of a head (Gurley et al. 2008). In this case, high 
levels of Smed- $\beta$ catenin 1 activity in the anterior blastema may be responsible for the observed phenotype ("two-tailed") (Fig. 3H).

Classical experiments in which a Janusheaded phenotype is obtained after dissection of extremely thin planarian fragments (Morgan 1898) also support this model, in which a morphogenetic gradient would be responsible for AP axial identity (Meinhardt 2009). More recent molecular data strongly suggest that the secreted Wnts are the morphogens responsible for the regulation of Smed- $\beta$ catenin 1 activity. The expression patterns of eight wnts from S. mediterranea have been reported (Petersen and Reddien 2008; Adell et al. 2009). Four of them show more or less restricted expression in the posterior region of the planarian body (Smed-wntP-1, Smed-wntP-2, Smed-wnt11-1, and Smed-wnt11-2), and are good candidates to be the morphogens responsible for regulation of Smed- $\beta$ catenin 1 activity and patterning the AP axis (see Fig. 3I). Remarkably, a recent publication reporting the systematic RNAi silencing of every $S$. mediterranea wnt shows that Smed-wntP-1 and Smed-wnt11-2 inhibition originates "Two-headed" and “Tailles" planarians (Adell et al. 2009), demonstrating that, at least, these two wnts signal through Smed- $\beta$ catenin 1 and would be the morphogens that pattern planarian AP axis. Despite not being expressed posteriorly, the remaining $S$. mediterranea wnts also show a very specific area of expression: Smed-wntP-3 and Smed-wnt2-1 mRNAs are detected in a few cells of the upper part of the pharynx and in both lateral regions of the head, respectively (Petersen and Reddien 2008); Smed-wntA and DjwntA (from the planarian species Dugesia japonica) are specifically expressed in the posterior part of the cephalic ganglia (Kobayashi et al. 2007; Adell et al. 2009); and Smed-wnt5 and Gt-wnt5 (from the planarian species Girardia tigrina) are expressed in the most external region of the CNS (Marsal et al. 2003; Adell et al. 2009) (Fig. 3I). Furthermore, inhibition of $D j-w n t A$ and Smed-wntA by RNAi induces the expansion of the brain posteriorly (Kobayashi et al. 2007; Adell et al. 2009), and inhibition of Smed-wnt5 induces the deflection and lateral expansion of the cephalic ganglia (Adell et al. 2009). The restricted expression pattern of each wnt, and the phenotype generated after Dj/Smed-wntA and Smed-wnt5 silencing, suggest that not only the AP axis, but the whole planarian body, could be patterned through the integrated morphogenetic activity of several wnts.

\section{Planarian Gap-junctional Communication}

The molecular process by which a morphogenetic gradient is established is not well understood, and even more difficult to explain in such large organisms as adult planarians (average size of $10 \mathrm{~mm}$ ). Although diffusion has been considered the main mechanism by which morphogens establish a gradient, active processes for the transport of morphogens have recently been proposed based on novel molecular data (Pfeiffer et al. 2000; Ibañes et al. 2006), which would enable long-range transmission of morphogenetic signals. One of these mechanisms is the direct transport of small and specific molecules through the cells using gap-junctional connections (Esser et al. 2006). Several innexins, the main components of invertebrate gap junctions, have been characterized from planarians (Nogi and Levin 2005; Oviedo and Levin 2007). Exposure of regenerating planarians to heptanol or hexanol, gap-junctions blockers, induced the regeneration of two-headed planarians, suggesting that this kind of cell-cell communication is required for proper AP axial establishment during planarian regeneration (Nogi and Levin 2005). Although a direct relationship between gap junctions and the wnt pathway remains to be established, wnts, or some intracellular element of the pathway, could be actively transported through gap junctions and thus establish a long-range differential wnt activity all along the planarian body.

\section{THE BMP PATHWAY REGULATES THE PLANARIAN DORSOVENTRAL AXIS}

$\mathrm{BMP} /$ Decapentaplegic (Dpp) proteins are examples of morphogens involved in key 
developmental processes such as DV patterning in vertebrates and Drosophila (for review, see De Robertis and Kuroda 2004; Ashe and Briscoe 2006; Ibañes and Izpisúa Belmonte 2008). Recently, it has been shown that several elements of the BMP pathway are conserved in freshwater planarians and, more importantly, that they are necessary for the re-establishment of a proper DV axis during regeneration (Molina et al. 2007, 2009; Orii and Watanabe 2007; Reddien et al. 2007). Thus, the RNAi silencing of the planarian homologs of BMP, Smad1, and Smad4, results in animals in which the dorsal side is transformed into a ventral one, in both regenerating and intact planarians. This ventralization is shown by the disappearance of dorsal molecular markers, together with the ectopic differentiation of ventral ones on the dorsal sides of the RNAitreated planarians (Molina et al. 2007; Reddien et al. 2007). Remarkably, in severe phenotypes, there is a duplication of the body margin (Fig. 4B), and an almost complete ectopic central nervous system develops on the ventralized dorsal side (Molina et al. 2007). This ventralization is also revealed by the appearance of mouth openings on the dorsal sides. Finally, in the most extreme cases, the

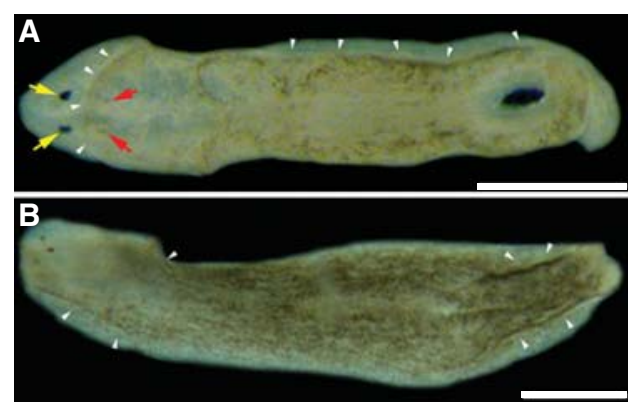

Figure 4. Disruption of the dorsoventral axis after BMP pathway silencing. (A) 21-d-old regenerating head pieces after Smed-Smad1 RNAi. White arrowheads mark the ectopic dorsoventral margin that delimits, which seems to be a second planarian differentiated on the dorsal side like a Siamese twin. Yellow arrows point to the original eyes. Red arrows point to ectopic eyes. (B) 21-d-old regenerating trunk piece after Smed-BMP RNAi. White arrowheads mark the duplicated body margin. Bars, $0.5 \mathrm{~mm}$.
DV axis appears to be duplicated, resulting in Siamese-like planarians (Fig. 4A).

Planarian BMP homolog is expressed in small clusters of very few cells all along the dorsal midline (Orii et al. 1998; Molina et al. 2007; Reddien et al. 2007), which is consistent with its function in DV patterning. It has also been suggested that the BMP pathway regulates the midline patterning during planarian regeneration (Reddien et al. 2007). In those planarians amputated parasagittally along their AP axis, the BMP pathway would instruct the formation of proper blastemas in those bilaterally asymmetric fragments (Reddien et al. 2007). Further studies are required to confirm that planarian BMP protein, or any of the recently identified homologs of the BMP signaling pathway inhibitors, such as the noggin family (Molina et al. 2009), diffuse dorsoventrally and therefore function as morphogens in the establishment of the DV axis.

\section{CONTROL OF THE DIFFERENTIATION OF THE PLANARIAN BRAIN IN THE ANTERIOR REGION}

Some of the classical experiments that have favored the hypothesis of diffusible molecule(s) responsible for the control of morphogenesis during planarian regeneration dealt with the differentiation of the cephalic ganglia and photoreceptors. Thus, a series of experiments by Etienne Wolff and Théodore Lender in the 1950s reported the role of the brain as an inductive agent for eye regeneration (Lender 1952, 1956a; for review, see Brøndsted 1969). Different results suggest that the planarian brain would produce a diffusible factor that would inhibit further brain differentiation (Lender 1956b; Steele and Lange 1977). This putative brain inhibitor would generate an AP gradient (Lender 1960). However, none of those putative diffusible molecules have been characterized yet.

\section{Nou-darake Restricts Brain Tissues in the Anterior Region}

Recent data suggesting a diffusible molecule that could act not as an inhibitor, but as an 
activator of brain differentiation, came from the study of nou-darake ("brain everywhere" in Japanese). Silencing of this gene by RNAi results in ectopic differentiation of brain tissues along posterior regions of the planarian body (Cebrià et al. 2002). Nou-darake is specifically expressed in the anterior region and codes for a transmembrane protein with similarity to the fibroblast growth factor (FGF) receptors, although it lacks the intracellular kinase domain. Sequence analyses, combinatorial RNAi silencing of nou-darake, and other planarian FGF receptors, as well as experiments on Xenopus, suggest that nou-darake could bind a planarian FGF and down-regulate FGF signaling (Cebrià et al. 2002; Agata and Umesono 2008). This putative FGF molecule would restrict brain differentiation to the planarian anterior region through a capture model (Agata and Umesono 2008). According to this model, a putative FGF would diffuse in the anterior region, promoting the differentiation of the brain within it. Nou-darake would trap the excess of FGF ligand, thus preventing its diffusion to more posterior regions. In the absence of nou-darake, the FGF molecule would diffuse more posteriorly, activating some unknown FGF receptor and triggering ectopic brain differentiation in those posterior regions (Cebrià et al. 2002; Agata and Umesono 2008). Unfortunately, the FGF molecules and receptors needed to test this hypothesis have not yet been characterized.

\section{Are Brain or Anterior Fates the Default States for Planarian Neoblasts?}

One interesting observation after nou-darake RNAi is that, in those amputated trunks in which both head and tail regions regenerate simultaneously, not only does the brain expand toward more posterior regions in the new head (Fig. 5A, black arrows), but ectopic brain tissues also differentiate within the new tail region (Fig. 5A, red arrowheads) (Cebrià et al. 2002). However, in the regenerated tail region, no further progression of ectopic brain toward more anterior or posterior regions is observed. In addition, the differentiation of ectopic brain tissues in the tail regions occurs at different times, depending on the level of amputation along the AP axis. Thus, ectopic brain is first observed after $3 \mathrm{~d}$ in regenerating head pieces, and after $5 \mathrm{~d}$ in bipolar regenerating trunks, but it does not appear at all in tail pieces regenerating a head (Fig. 5A, red arrowheads).

If nou-darake blocks the diffusion of a putative brain activator from the planarian anterior region, how does nou-darake RNAi lead to that initial brain differentiation in the most posterior regions? And why is there no further progression of those ectopic posterior brain tissues? So far, we do not have clear answers for those questions. Perhaps neoblasts are committed by default to brain or anterior fate, and then they may be induced to differentiate into something else by a later signal. Imagine then that, after amputation, a brain activator (BA) is produced within the blastema. In a wild-type anterior blastema, this BA would induce normal brain differentiation. In a wild-type posterior blastema, this putative BA may also be up-regulated just after amputation, but somehow expression of nou-darake in that posterior blastema would block its function. In a nou-darake RNAi knockdown animal, the BA would be up-regulated in the posterior blastema and would instruct some neoblasts to differentiate into brain cells. But then, a second signal telling the blastema to form a tail rather than a head would somehow block the action of this BA and, consequently, no further progression of ectopic brain tissues would occur. This hypothesis implies that the BA and nou-darake should be expressed, even at a very low level, in the posterior blastema during the first hours after amputation before the signal responsible for determining anterior versus posterior is received (nou-darake is not detected in posterior blastemas by in situ hybridization but its possible expression there should be checked by more sensitive techniques such as RT-PCR).

Recently, it has been shown that the Wnt/ $\beta$-catenin pathway is responsible for establishing the AP axis during planarian regeneration (Gurley et al. 2008; Iglesias et al. 2008; Petersen and Reddien 2008). An interesting observation after APC-1 RNAi is that certainly the 
T. Adell, F. Cebrià, and E. Saló

A
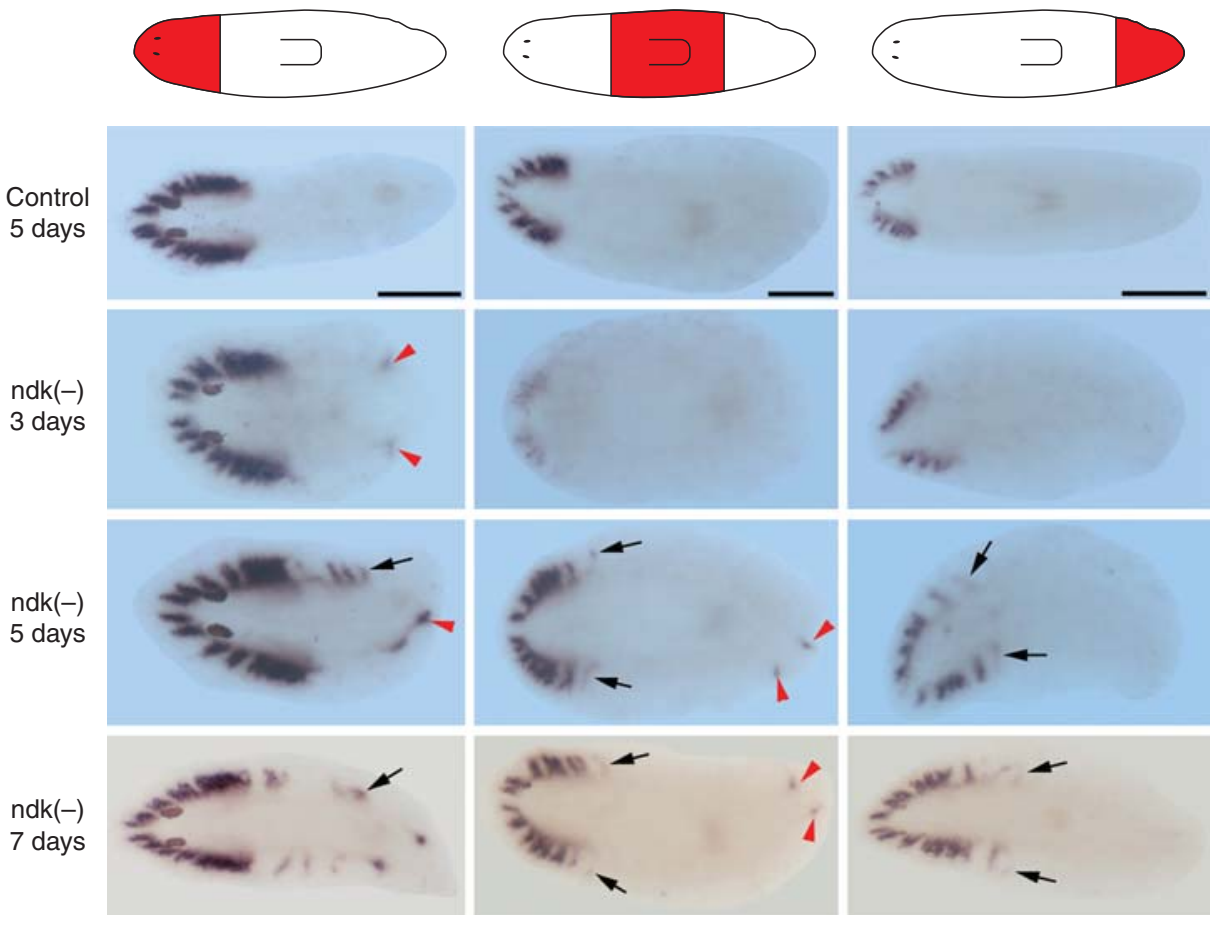

B Wild type
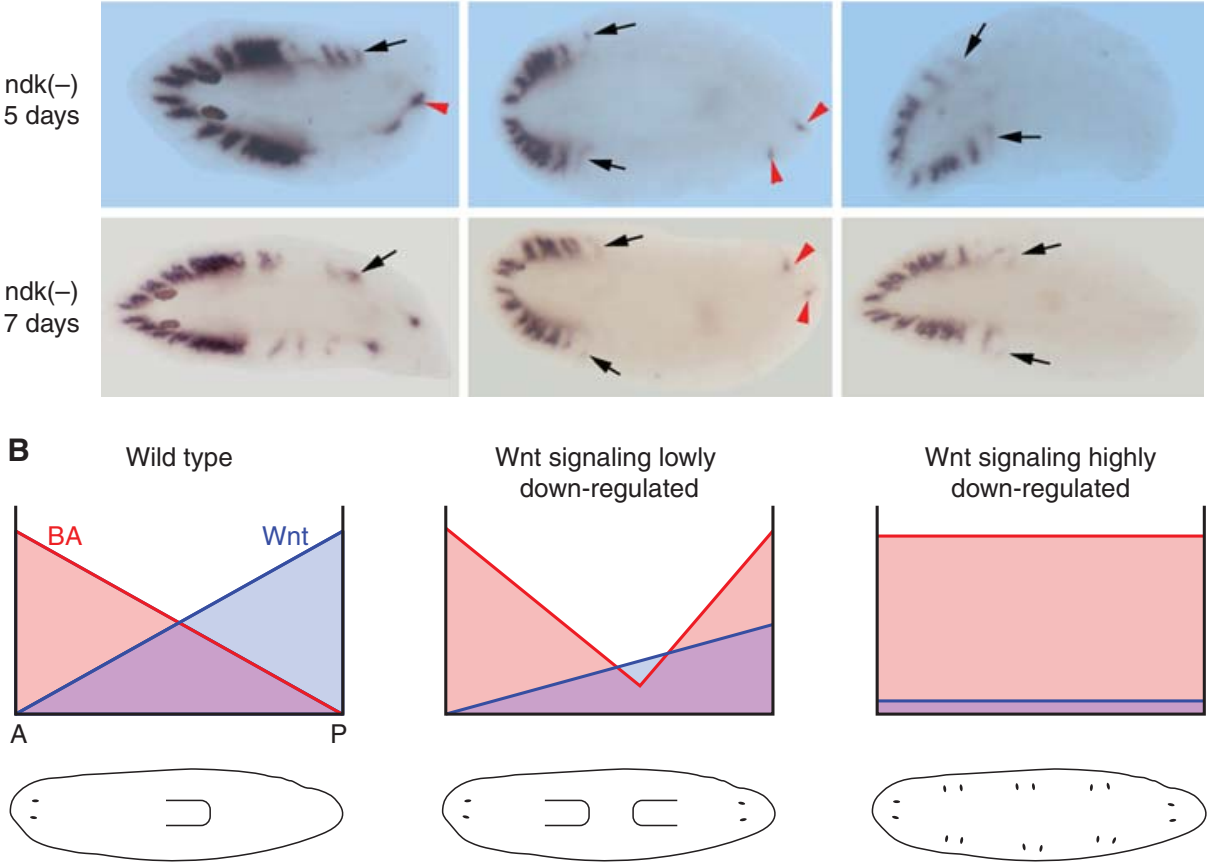

Figure 5. Effects of nou-darake silencing on planarian regeneration. (A) Whole-mount in situ hybridizations with a glutamate receptor homolog (a brain-specific marker) on regenerating head (left panels), bipolar trunk (central panels), and tail (right panels) segments in control and nou-darake (ndk) RNAi animals. The schematic drawings show in red the amputation level of the regenerating pieces shown below. (Adapted from Cebrià et al. 2002.) (B) Putative combinatorial action of gradients of a brain activator (BA) and Wnt activity in regulating neural differentiation along the AP axis (see text for details). Bar, $0.5 \mathrm{~mm}$ (head pieces); $1 \mathrm{~mm}$ (trunk pieces); and $0.5 \mathrm{~mm}$ (tail pieces).

"anterior" blastema differentiates into a tail instead of a head (Gurley et al. 2008). However, in the regenerated central nervous system (CNS), in those APC-1-silenced planarians, although ventral nerve cords (vnc) are clearly differentiated within the new region, they clearly thicken close to the blastema/ stump boundary (Gurley et al. 2008). This thickening of the vnc could correspond to brain tissues. If brain differentiation occurs after APC-1 silencing, it would be consistent with the hypothesis of brain or anterior fate as 
a default state. Thus, in an APC-1 RNAi planarian regenerating anteriorly, the neoblasts would begin differentiating into brain cells in the first stages immediately after amputation. Then, as a result of APC-1 silencing, the blastema would receive a signal to regenerate a tail rather than a head. The neoblasts would then stop making a new brain and only residual brain cells would remain. Brain-specific markers should be used to examine whether brain cells start differentiating before the lack of function of APC-1 is translated into a change of blastema identity.

Is There a Connection Between Nou-darake and the Canonical Wnt Pathway?

As there are similarities between the progression of ectopic CNS differentiation after nou-darake and $\beta$-catenin RNAi, it seems reasonable to wonder up to what extent these two pathways might be connected. In both cases, in bipolar regenerating trunk pieces, there is an AP progression of CNS differentiation. Also, from the early stages of differentiation, ectopic brain tissues differentiate within the posterior blastemas (Cebrià et al. 2002; Iglesias et al. 2008). As $\beta$-catenin confers posterior identity, we could hypothesize that after Smed- $\beta$ catenin1 RNAi, a putative inhibitory action of the Wnt pathway on the predicted BA would disappear and, as a consequence, it could diffuse, resulting in ectopic brain differentiation along the AP axis. In animals with a low level of silencing of the Wnt pathway, cephalic ganglia would develop only in posterior regions, because in the central region, the inhibitory action of the Wnt pathway would be higher than the activity of the BA. On the other hand, in animals with a high level of silencing of the Wnt pathway, the BA could be up-regulated all along the AP axis, resulting in hypercephalized planarians (Fig. 5B). Thus, this putative BA could be regulated directly and/or indirectly by both nou-darake and Wnt signaling pathways.

Recently, it has been reported that a planarian WntA is important for the patterning of the posterior brain, but does not further affect AP polarity (Kobayashi et al. 2007). Similarly, nou-darake restricts the differentiation of brain tissues within the anterior region without affecting AP identity, as that anterior region is not expanded posteriorly (Cebrià et al. 2002). This suggests that the mechanisms that determine axial polarity can be uncoupled from those that control the patterning and differentiation of distinct structures along this AP axis. Even though WntA RNAi also results in a posterior expansion of brain tissues, no direct relationship between this WntA and nou-darake has been found (Kobayashi et al. 2007). Further detailed analyses should unravel the relationship, if any, between nou-darake and the Wnt pathway in neural differentiation and AP polarity.

\section{CONCLUDING REMARKS}

Planarian plasticity is demonstrated not only by their strong regenerative capacity, but also because intact adult animals are constantly readjusting their body proportions. In this sense, planarians represent an excellent model in which to study the action of morphogenetic gradients in two nonembryonic contexts: regeneration and homeostasis. We have discussed recent data suggesting that the $\mathrm{Wnt} / \beta$-catenin and BMP pathways might control planarian polarity by the action of morphogenetic gradients. We have also discussed the possible interaction between $\mathrm{Wnt} / \beta$-catenin and FGF pathways in controlling neuronal differentiation along the AP axis. Further analysis should demonstrate whether these secreted molecules function as real morphogens and how they interact to control planarian morphogenesis.

\section{ACKNOWLEDGMENTS}

We thank Marta Iglesias and $\mathrm{M}^{\mathrm{a}}$ Dolores Molina for suggestions and helpful discussion. We thank Marta Iglesias and $\mathrm{M}^{\mathrm{a}}$ Dolores Molina for providing images shown in Figures 1 and 4, respectively. We thank Carlos Molina for drawing the three-dimensional planarian in Fig. 3I, and Robin Rycroft for checking the English. T.A. was supported by C-RED (Generalitat de Catalunya). F.C. is a Ramón y 
Cajal researcher (Ministerio de Educación y Ciencia, Spain). This study was supported by grants BFU2005-00422 and BFU2008-01544/ BMC from the Ministerio de Educación y Ciencia, Spain; and grant 2005SGR00769 from AGAUR (Generalitat de Catalunya) to E.S. T.A. and F.C. contributed equally.

\section{REFERENCES}

Adell T, Saló E, Boutros M, Bartscherer K. 2009. Smed-Evi/ Wntless is required for $\beta$-catenin-dependent and -independent processes during planarian regeneration. Development 136: 905-910.

Agata K, Umesono Y. 2008. Brain regeneration from pluripotent stem cells in planarian. Philos Trans $R$ Soc Lond B Biol Sci 363: 2071-2078.

Ashe HL, Briscoe J. 2006. The interpretation of morphogen gradients. Development 133: 385-394.

Blackstone NW. 2006. Charles Manning Child (1869-1954): The past, present, and future of metabolic signaling. J Exp Zool B Mol Dev Evol 306: 1-7.

Brøndsted HV. 1969. Planarian regeneration. Pergamon, Oxford.

Cebrià F, Kobayashi C, Umesono Y, Nakazawa M, Mineta K, Ikeo K, Gojobori T, Itoh M, Taira M, Sánchez Alvarado A, Agata K. 2002. FGFR-related gene nou-darake restricts brain tissues to the head region of planarians. Nature 419: $620-624$.

Child CM. 1911. Studies on the dynamics of morphogenesis and inheritance in experimental reproduction. I The axial gradient in Planaria dorotocephala as a limiting factor in regulation. J Exp Zool 10: 265-320.

Child CM. 1941. Problems and patterns of development. University Chicago Press, Chicago.

Croce JC, McClay DR. 2006. The canonical Wnt pathway in embryonic axis polarity. Semin Cell Dev Biol 2: 168-174.

De Robertis EM, Kuroda H. 2004. Dorsal-ventral patterning and neural induction in Xenopus embryos. Annu Rev Cell Dev Biol 20: 285-308.

Esser AT, Smith KC, Weaver JC, Levin M. 2006. Mathematical model of morphogen electrophoresis through gap junctions. Dev Dyn 8: 2144-2159.

Flickinger RA. 1959. A gradient of protein synthesis in planaria and reversal of axial polarity of regenerates. Growth 23: $251-271$.

Gurley KA, Rink JC, Sánchez-Alvarado A. 2008. $\beta$-catenin defines head versus tail identity during planarian regeneration and homeostasis. Science 319: 323-327.

Handberg-Thorsager M, Fernandez E, Saló E. 2008. Stem cells and regeneration in planarians. Front Biosci 13: 6374-6394.

Holland LZ. 2002. Heads or tails? Amphioxus and the evolution of anterior-posterior patterning in deuterostomes. Dev Biol 24: 209-228.

Huxley JS, de Beer GA. 1934. The elements of experimental embryology. Cambridge University Press, Cambridge.
Ibañes M, Izpisúa Belmonte JC. 2008. Theoretical and experimental approaches to understand morphogen gradients. Mol Syst Biol 4: 176.

Ibañes M, Kawakami Y, Rasskin-Gutman D, Belmonte JC. 2006. Cell lineage transport: A mechanism for molecular gradient formation. Mol Syst Biol 2: 57.

Iglesias M, Gomez-Skarmeta JL, Saló E, Adell T. 2008. Silencing of Smed- $\beta$ catenin 1 generates radial-like hypercephalized planarians. Development 135: 1215-1221.

Johnson JR. 1822. Observations on the genus planaria. Philos Trans R Soc Lond Part II: 437-446.

Kohl DM, Flickinger RA. 1966. The role of DNA synthesis in the determination of axial polarity in regenerating planarians. Biol Bull 131: 322-330.

Kobayashi C, Saito Y, Ogawa K, Agata K. 2007. Wnt signaling is required for antero-posterior patterning of the planarian brain. Dev Biol 306: 714-724.

Lender TH. 1952. Sur la régénération des yeux de la planarie Polycelis nigra en presénce de broyats de la région antérieure du corps. Bull Biol Fr Belg 86: 140-215.

Lender TH. 1956a. Recherches experimentales sur la nature et les propriétés de l'inducteur de la régénération des yeux de la planarie Polycellis nigra. J Embryol Exp Morpol 4: 196-216.

Lender TH. 1956b. L’inhibition de la régénération du cervau des planaries Polycelis nigra (Ehr.) et Dugesia lugubris (O. Schm.) en présence de broyats de têtes ou de queues. Bull Soc Zool Fr 81: 192.

Lender T. 1960. The specific inhibition of the differentiation of the brain of fresh water planarians during regeneration (in French). J Embryol Exp Morphol 8: 291-301.

Lewis J, Slack JM, Wolpert L. 1977. Thresholds in development. J Theor Biol 65: 579-590.

Logan CY, Miller JR, Ferkowicz MJ, McClay DR. 1999. Nuclear $\beta$-catenin is required to specify vegetal cell fates in the sea urchin embryo. Development 126: 345-357.

Marsal M, Pineda D, Saló E. 2003. Gtwnt-5 a member of the wnt family expressed in a subpopulation of the nervous system of the planarian Girardia tigrina. Gene Expr Patterns 4: 489-495.

Meinhardt H. 2009. Beta-catenin and axis formation in planarians. Bioessays 31: 5-9.

Meinhardt H. 1978. Space-dependent cell determination under the control of morphogen gradient. J Theor Biol 74: $307-321$.

Meinhardt H, Gierer A. 1974. Applications of a theory of biological pattern formation based on lateral inhibition. J Cell Sci 15: 321-346.

Molina MD, Saló E, Cebrià F. 2007. The BMP pathway is essential for re-specification and maintenance of the dorsoventral axis in regenerating and intact planarians. Dev Biol 311: 79-94.

Molina MD, Saló E, Cebrià F. 2009. Expression pattern of the expanded noggin gene family in the planarian Schmidtea mediterranea. Gene Expression Patterns. (in press).

Morgan TH. 1898. Experimental studies of the regeneration of Planaria maculata. Arch Entwickelungsmech Org 7: 364-397.

Morgan TH. 1901. Regeneration. Macmillan, New York. 
Morgan TH. 1904. Polarity and axial heteromophosis. Am Nat 38: 502-505.

Morgan TH. 1905. "Polarity" considered as a phenomenon of gradation of materials. J Exp Zool 2: 495-506.

Nogi T, Levin M. 2005. Characterization of innexin gene expression and functional roles of gap-junctional communication in planarian regeneration. Dev Biol 287: 314-335.

Orii H, Watanabe K. 2007. Bone morphogenetic protein is required for dorso-ventral patterning in the planarian Dugesia japonica. Dev Growth Differ 49: 345-349.

Orii H, Kato K, Agata K, Watanabe K. 1998. Molecular cloning of bone morphogenetic protein (BMP) gene from the planarian Dugesia japonica. Zool Sci 15: 871-877.

Oviedo NJ, Levin M. 2007. smedinx-11 is a planarian stem cell gap junction gene required for regeneration and homeostatis. Development 134: 3121-3131.

Pallas PS. 1774. Spicilegia zoologica quibus novae imprimis et obscurae animalium species iconibus, descriptionibus atque commentariis illustrantur. Berolini, Prostant, Apud Gottl.

Petersen CP, Reddien PW. 2008. Smed- $\beta$ catenin-1 is required for anteroposterior blastema polarity in planarian regeneration. Science 319: 327-330.

Pfeiffer S, Alexandre C, Calleja M, Vincent JP. 2000. The progeny of wingless-expressing cells deliver the signal at a distance in Drosophila embryos. Curr Biol 10: 321-324.

Reddien PW, Sánchez Alvarado A. 2004. Fundamentals of planarian regeneration. Annu Rev Cell Dev Biol 20: 725-757.

Reddien PW, Bermange AL, Kicza AM, Sánchez Alvarado A. 2007. BMP signaling regulates the dorsal planarian midline and is needed for asymmetric regeneration. Development 134: 4043-4051.

Reya T, Clevers H. 2005. Wnt signalling in stem cells and cancer. Nature 434: 843-850.
Saló E. 1984. "Formació del blastema i re-especificació del patró durant la regeneració de les planàries Dugesia (S) mediterranea i Dugesia (G) tigrina: anàlisi morfològica, cellular i bioquímica" $\mathrm{PhD}$ thesis. University of Barcelona, Spain.

Saló E. 2006. The power of regeneration and the stem-cell kingdom: freshwater planarians (Platyhelminthes). Bioessays 28: $546-559$.

Saló E, Baguñà J. 1985. Proximal and distal transformation during intercalary regeneration in the planarian Dugesia(S)tigrina. Roux's Arch Dev Biol 194: 364-368.

Saló E, Baguñà J. 2002. Regeneration in planarians and other worms: New findings, new tools and new perspectives. J Exp Zool 292: 528-539.

Sánchez Alvarado A. 2006. Planarian regeneration: Its end is its beginning. Cell 124: 241-245.

Schaller HC, Schmidt T, Grimmelikhuijzen CJP. 1979. Separation and specificity of action of four morphogens from hydra. Wilhelm Roux' Arch Entwicklungsmech Org 186: $138-149$.

Sivickis PB. 1931. A quantitative study of regeneration along the main axis of the triclad body. Arch Zool Ital 16: $430-449$.

Slack JMW. 1987. Morphogenetic gradients-past and present. Trends Biol Sci 12: 200-204.

Steele VE, Lange CS. 1977. Characterization of an organspecific differentiator substance in the planarian Dugesia etrusca. J Embryol Exp Morphol 37: 159-172.

Strigini M, Cohen SM. 2000. Wingless gradient formation in the Drosophila wing. Curr Biol 10: 293-300.

Wikramanayake AH, Hong M, Lee PN, Pang K, Byrum CA, Bince JM, Xu R, Martindale MQ. 2003. An ancient role for nuclear $\beta$-catenin in the evolution of axial polarity and germ layer segregation. Nature 426: 446-450.

Wolpert L. 1969. Positional information and the spatial pattern of cellular differentiation. J Theor Biol 25: 1-47. 


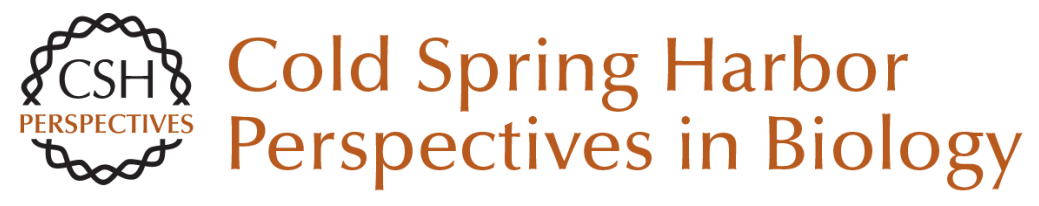

\section{Gradients in Planarian Regeneration and Homeostasis}

Teresa Adell, Francesc Cebrià and Emili Saló

Cold Spring Harb Perspect Biol 2010; doi: 10.1101/cshperspect.a000505 originally published online July 15, 2009

\section{Subject Collection Generation and Interpretation of Morphogen Gradients}

Regulation of Organ Growth by Morphogen Gradients

Gerald Schwank and Konrad Basler

Signaling Gradients during Paraxial Mesoderm

Development Alexander Aulehla and Olivier Pourquié

Morphogen Gradient Formation

Ortrud Wartlick, Anna Kicheva and Marcos

González-Gaitán

Nodal Morphogens

Alexander F. Schier

Gradients and the Specification of Planar Polarity

in the Insect Cuticle

David Strutt

Vertebrate Limb Development: Moving from

Classical Morphogen Gradients to an Integrated

4-Dimensional Patterning System Jean-Denis Bénazet and Rolf Zeller

Establishing and Interpreting Graded Sonic

Hedgehog Signaling during Vertebrate Neural

Tube Patterning: The Role of Negative Feedback Vanessa Ribes and James Briscoe

Systems Biology of the Self-regulating

Morphogenetic Gradient of the Xenopus Gastrula Jean-Louis Plouhinec and E. M. De Robertis
Gradients in Planarian Regeneration and Homeostasis

Teresa Adell, Francesc Cebrià and Emili Saló

Shaping Morphogen Gradients by Proteoglycans Dong Yan and Xinhua Lin

Forming Patterns in Development without Morphogen Gradients: Scattered Differentiation and Sorting Out

Robert R. Kay and Christopher R.L. Thompson

Robust Generation and Decoding of Morphogen Gradients

Naama Barkai and Ben-Zion Shilo

Models for the Generation and Interpretation of

Gradients

Hans Meinhardt

Graded Dorsal and Differential Gene Regulation in the Drosophila Embryo

Gregory T. Reeves and Angelike Stathopoulos

Chemical Gradients and Chemotropism in Yeast Robert A. Arkowitz

Gradients in the Brain: The Control of the Development of Form and Function in the Cerebral Cortex

Stephen N. Sansom and Frederick J. Livesey

For additional articles in this collection, see http://cshperspectives.cshlp.org/cgi/collection/

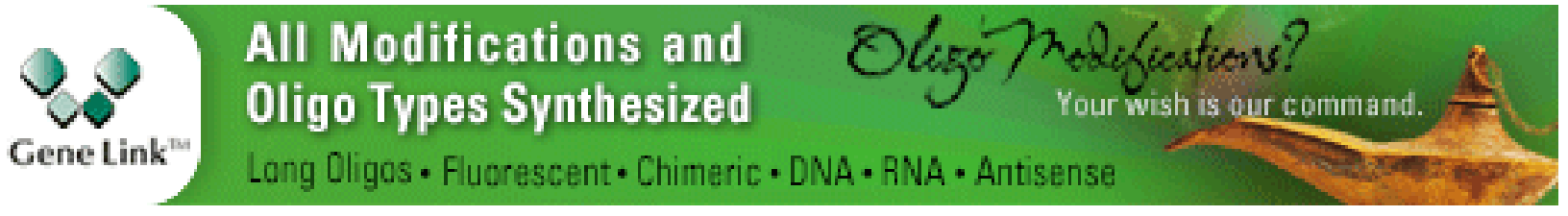


For additional articles in this collection, see http://cshperspectives.cshlp.org/cgi/collection/

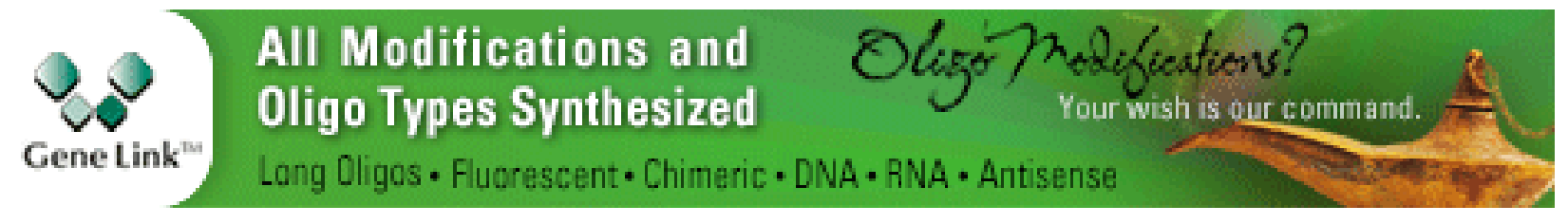

Copyright @ 2010 Cold Spring Harbor Laboratory Press; all rights reserved 